more frequent reason for consultation in the elderly population, while arthralgia was more frequent in the young population. Young subjects more frequently had peripheral joints complaints. Degenerative and tumor pathologies were more common in the elderly population, while inflammatory, septic, and tendon pathologies were more prominent in the young population. Regarding treatments, non-steroidal anti-inflammatory drugs were more prescribed in young subjects, while the other treatments had a homogeneous distribution in the two groups.

Conclusion: In our emergency unit, the epidemiological distribution of our patients according to age matches the general epidemiological characteristics of rheumatological pathologies: inflammatory causes are more frequent in young ages, while degenerative pathologies are found at a later age.

REFERENCES:

[1] Kobak S, Bes C. An autumn tale: geriatric rheumatoid arthritis. Therapeutic Advances in Musculoskeletal. 2018 Jan;10(1):3-11.

[2] Loeser RF. The Role of Aging in the Development of Osteoarthritis. Trans Am Clin Climatol Assoc. 2017;128:44-54.

Table 1. Patients' characteristics depending on age

\begin{tabular}{|c|c|c|}
\hline & $\begin{array}{c}\geq 65 \text { years (81 cases) } \\
19,9 \%\end{array}$ & $\begin{array}{c}<65 \text { years }(326 \text { cases }) \\
80,1 \%\end{array}$ \\
\hline \multicolumn{2}{|l|}{ Social coverage } & 0,38 \\
\hline Public health assistance scheme & $32(39,5 \%)$ & $122(37,42 \%)$ \\
\hline Public/Private insurance & $21(25,92 \%)$ & $91(27,91 \%)$ \\
\hline Without & $28(34,57 \%)$ & $113(34,66 \%)$ \\
\hline Profession & Précisé $=45$ & Précisé $=162$ \\
\hline Without & $36(80 \%)$ & $104(64,2 \%)$ \\
\hline Retirees & $7(15,55 \%)$ & $4(2,47 \%)$ \\
\hline Farmer & $1(2,22 \%)$ & $1(0,62 \%)$ \\
\hline Intermediate professions & $1(2,22 \%)$ & $18(11,11 \%)$ \\
\hline Higher intellectual professions & 0 & $12(7,41 \%)$ \\
\hline Employees & 0 & $9(5,55 \%)$ \\
\hline Traders and craftsmen & 0 & $9(5,55 \%)$ \\
\hline Workers & 0 & $5(3,09 \%)$ \\
\hline \multicolumn{3}{|l|}{ Reason for consultation } \\
\hline Back pain & $35(43,2 \%)$ & $137(48,15 \%)$ \\
\hline Radiculalgia & $22(27,16 \%)$ & $55(16,87 \%)$ \\
\hline Arthralgias & $34(41,97 \%)$ & $165(50,61 \%)$ \\
\hline Arthritis & $10(12,34 \%)$ & $37(11,35 \%)$ \\
\hline \multicolumn{3}{|l|}{ Joint involvement } \\
\hline Axial & $41(50,61 \%)$ & $170(52,15 \%)$ \\
\hline Peripheral & $53(65,43 \%)$ & $248(76,07 \%)$ \\
\hline \multicolumn{3}{|l|}{ Duration of symptoms } \\
\hline Acute $(<3$ weeks $)$ & $21(25,92 \%)$ & $73(22,39 \%)$ \\
\hline Chronic ( $\geq 3$ weeks) & $60(74,08 \%)$ & $253(77,61 \%)$ \\
\hline \multicolumn{3}{|l|}{ Diagnoses } \\
\hline Osteoarthritis & $30(58,82 \%)$ & $89(48,9 \%)$ \\
\hline Knee osteoarthritis & $21(41,17 \%)$ & $50(27,47 \%)$ \\
\hline Lumbar osteoarthritis & $16(31,37 \%)$ & $44(24,17 \%)$ \\
\hline Septic & $2(3,92 \%)$ & $11(6,04 \%)$ \\
\hline Metabolic & $6(13,35 \%)$ & $9(4,94 \%)$ \\
\hline Inflammatory & $1(1,96 \%)$ & $22(12,08 \%)$ \\
\hline Tumor & $3(5,88 \%)$ & $2(1,09 \%)$ \\
\hline Tendinopathies & $3(9,68 \%)$ & $29(15,93 \%)$ \\
\hline \multicolumn{3}{|l|}{ Treatments } \\
\hline Analgesics & $47(71,21 \%)$ & $155(63,52 \%)$ \\
\hline NSAIDs & $19(28,78 \%)$ & $118(48,36 \%)$ \\
\hline Corticosteroids & $1(1,51 \%)$ & $2(0,82 \%)$ \\
\hline Local treatments & $18(27,27 \%)$ & $72(29,5 \%)$ \\
\hline Symptomatic slow-acting drugs & $19(28,78)$ & $49(20,08 \%)$ \\
\hline DMARDs & $0(0 \%)$ & $2(0,82 \%)$ \\
\hline
\end{tabular}

Disclosure of Interests: None declared

DOI: 10.1136/annrheumdis-2021-eular.2734

\section{AB0830 ADVERSE PERINATAL OUTCOMES AND CONGENITAL DEFECTS IN MEXICAN WOMEN WITH AUTOIMMUNE RHEUMATIC DISEASES}

R. A. Rodriguez Chavez ${ }^{1}$, C. M. Skinner Taylor ${ }^{1}$, L. Pérez Barbosa', G. A. López-Uriarte ${ }^{2}$, E. Barriga-Maldonado', G. Figueroa-Parra ${ }^{1}$, I. PerezOnofre $^{1}$, A. Elizondo-Plazas ${ }^{2}$, L. G. Espinosa Banuelos ${ }^{1}$, R. Moyeda Martinez ${ }^{1}$, A. Y. Lujano Negrete ${ }^{1}$, D. Á. Galarza-Delgado ${ }^{1} .{ }^{1}$ Hospital Universitario Dr. José Eleuterio González, Rheumatology Service, Monterrey, Mexico; ${ }^{2}$ Hospital Universitario Dr. José Eleuterio González, Genetics Department, Monterrey, Mexico

Background: Pregnancy in women with autoimmune rheumatic diseases (ARD) is associated with an increase in the risk of adverse perinatal outcomes and birth defects. Many factors have been attributed to these including medication employed and maternal autoantibodies. The national prevalence of congenital anomalies in newborns in Mexico is estimated to be 73.9 per 10,000 births but the rate of these in Mexican women with ARD is unknown.

Objectives: This study aims to describe the frequency of adverse perinatal outcomes and congenital defects in Mexican women with ARD.

Methods: We performed a descriptive and prospective study that included all pregnant patients with ARDs from the clinic of pregnancy and rheumatic diseases in the University Hospital "Dr. José Eleuterio González" who gave birth between February 2019 to November 2020. Demographic information, pregnancy outcome, and congenital defects were prospectively evaluated. Congenital defects were clinically confirmed by a clinical geneticist.

Results: A total of 40 women were taken in the final analyses. The ARD diagnosis is shown in graphic 1. Rheumatoid arthritis was the most frequent diagnosis that had an adverse perinatal outcome with $4(40 \%)$ and congenital defects in $2(40 \%)$. No complications or birth defects were reported in 25 $(62.5 \%)$. The adverse perinatal outcome was reported in $10(25 \%)$ women and congenital defects in $5(12.5 \%)$. The most frequent adverse perinatal outcomes were preterm birth $6(15 \%)$ and the second most frequent miscarriage $3(7.5 \%)$ (Table 1 below).

Conclusion: We found a high frequency (12.5\%) of adverse perinatal outcomes and congenital defects in Mexican women with ARD. Multidisciplinary groups and clinics are needed to adequately serve this complex population and reduce morbidity and mortality. A multidisciplinary approach before, during, and after pregnancy in patients with ARD may improve morbidity and mortality.

\section{REFERENCES:}

[1] Vinet, E., Bernatsky, S. (2017). Outcomes in Children Born to Women with Rheumatic Diseases. Rheum Dis Clin N Am. http://dx.doi.org/10.1016/j. rdc.2016.12.006.

[2] Krishnan AN, Sable CA, Donofrio MT.(2008). Spectrum of fetal echocardiographic findings in fetuses of women with clinical or serologic evidence of systemic lupus erythematosus. J Matern Fetal Neonatal Med. 21(11):776-82.

[3] NAVARRETE HERNANDEZ, Eduardo et al. Prevalencia de malformaciones congénitas registradas en el certificado de nacimiento y de muerte fetal: México, 2009-2010. Bol. Med. Hosp. Infant. Mex. [online]. 2013, vol.70, n.6, pp.499-505.

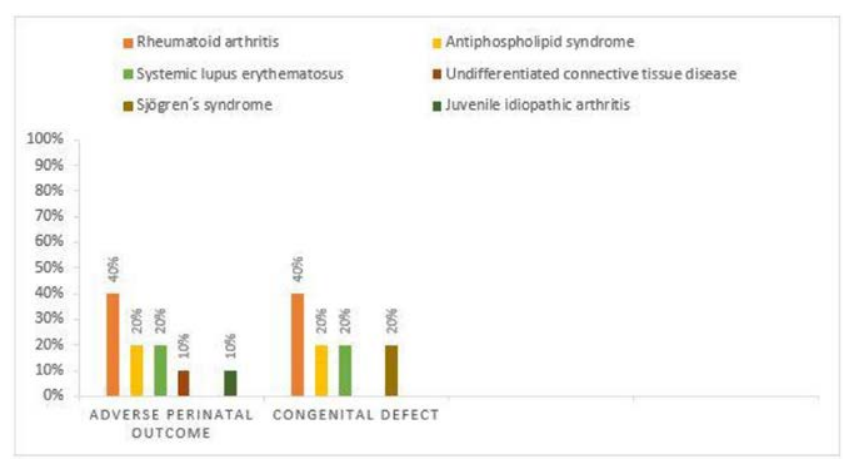

Graphic 1. Percentage of adverse perinatal outcomes and congenital defects due to rheumatic disease.

Table 1. Frequency and percentages of adverse perinatal outcomes and congenital defects.

\begin{tabular}{lcc}
\hline & $\begin{array}{c}\text { Adverse perinatal } \\
\text { outcome }(\mathrm{n}=\mathbf{1 0}) \mathbf{2 5 \%}\end{array}$ & $\begin{array}{c}\text { Congenital defects } \\
(\mathrm{n}=5) \mathbf{5 2 . 5} \%\end{array}$ \\
\hline Preterm birth & $6(15 \%)$ & - \\
Miscarriage & $3(7.5 \%)$ & - \\
Stillbirth & $1(2.5 \%)$ & - \\
Congenital heart disease* & - & $1(2.5 \%)$ \\
$\begin{array}{l}\text { Congenital cardiac block with pace- } \\
\quad \text { maker placement }\end{array}$ & - & $1(2.5 \%)$ \\
Krabbe's disease & - & $1(2.5 \%)$ \\
Preauricular appendix & - & $1(2.5 \%)$ \\
Diabetic fetopathy & - & $1(2.5 \%)$ \\
\hline
\end{tabular}

*Tetralogy of Fallot

Disclosure of Interests: None declared

DOI: 10.1136/annrheumdis-2021-eular.3270 